\title{
New Stent Technologies
}

\author{
Yukio Ozaki, Andonis G. Violaris, and Patrick W. Serruys
}

Coronary stents were developed to overcome the two main limitations of balloon angioplasty, acute occlusion and long-term restenosis. Coronary stents can tack back intimal flaps and seal the dissected vessel wall, thereby treating acute or threatened vessel closure after unsuccessful balloon angioplasty. After successful balloon angioplasty, stents can prevent late vessel remodeling (chronic vessel recoil) by mechanically enforcing the vessel wall and resetting the vessel size, resulting in a low incidence of restenosis. Al currently available stents are composed of metal, and the long-term effects of their implantation in the coronary arteries are still not clear. Because of the metallic surface, they are also thrombogenic; therefore, rigorous antiplatelet or anticoagulant therapy is theoretically required. Furthermore, they have an imperfect compromise between scaffolding properties

C ORONARY stents were developed to overcome the two main limitations of balloon angioplasty, acute occlusion and long-term restenosis. Coronary stents can tack back intimal flaps and seal the dissected vessel wall, thereby treating acute or threatened vessel closure after unsuccessful balloon angioplasty. After successful balloon angioplasty, stenting can prevent late vessel remodeling (chronic vessel recoil) by mechanically enforcing the vessel wall and resetting the vessel size, resulting in a low incidence of restenosis. These theoretical advantages of coronary stenting have been tested in two major randomized trials. ${ }^{1,2}$ Both the Belgium Netherlands Stent Study (Benestent) and Stent Restenosis Study (STRESS) confirmed the theoretical advantages of coronary stenting by showing a reduction in angiographic restenosis and clinical events during follow-up examination. ${ }^{1,2}$ This reduction in restenosis was achieved by a greater luminal gain despite the accommodation of a greater absolute loss in lumen diameter in the stent group, suggesting greater neointimal hyperplasia in this group. The reduction in long-term restenosis was counterbalanced by bleeding complications related to the anticoagulant therapy. Therefore, a number of limitations have to be overcome before coronary stenting achieves its full potential.

\section{CURRENTLY AVAILABLE STENTS}

The currently available stents, a description of their design, and the year of their clinical and flexibility, resulting in an unfavorable interaction between stents and unstable or thrombus-laden plaque. Finally, they still induce substantial intimal hyperplasia that may result in restenosis. Future stents can be made less thrombogenic by modifying the metallic surface or coating it with an antithrombotic agent or a membrane eluting an antithrombotic drug. The unfavorable interaction with the unstable plaque and the thrombus burden can be overcome by covering the stent with a biological conduit, such as a vein, or a biodegradable material that can be endogenous, such as fibrin, or exogenous, such as a polymer. Finally, the problem of persisting induction of intimal hyperplasia may be overcome with the use of either a radioactive stent or a stent eluting an antiproliferative drug.

Copyright $(1996$ by W.B. Saunders Company

introduction are listed in Table 1 and are shown in Fig 1. In the absence of prospective randomized interstent comparative trials, it is difficult to draw conclusions on the relative merits and demerits of each stent design. However, individual experience and registry data from each stent allow preliminary impressions to be made on the advantages and limitations of each stent.

\section{Wallstent}

The Wallstent (Schneider, Bulach, Switzerland) was the pioneer of stents ${ }^{3-5}$ through which we learned the risk profile and indications for coronary stenting and the necessity and adverse effects of antithrombotic measures. The new less-shortening Wallstent has been developed recently with a change in the braiding angle, and results of the first clinical implantation of this second generation stent in coronary vein grafts have been promising. ${ }^{6}$ The unique advantages of the Wallstent include the extensive range of diameters and lengths available, thereby allowing the Wallstent to be used for the management of long spiral dissections ${ }^{7}$ and for vessel reconstruction. 8 The sheathed "balloon-

From the Catheterization Laboratory, Thoraxcenter, Erasmus University, Rotterdam, The Netherlands.

Address reprint request to Patrick W. Serriys, MD, PhD, FACC, FESC, Catheterization Laboratory, Thoraxcenter, Erasmus University Rotterdam, Postbus 1738, 3000 DR Rotterdam, The Netherlands.

Copyright $\odot 1996$ by W.B. Saunders Company

0033-0620/96/3902-0004\$5.00/0 
Table 1. Currently Available Stents Undergoing Clinical Evaluation

\begin{tabular}{|c|c|c|c|c|c|c|c|}
\hline Coronary Stent & Design & Deployment & Premounted & Delivery & $\begin{array}{l}\text { Diameter } \\
(\mathrm{mm})\end{array}$ & $\begin{array}{l}\text { Length } \\
\text { (mm) }\end{array}$ & $\begin{array}{l}\text { First Clinical } \\
\text { Implantation }\end{array}$ \\
\hline Wallstent & Wire mesh & Self-expanding & $\begin{array}{l}\text { Balloon } \\
\text { not required }\end{array}$ & Over-the-wire & $3.5-6.0$ & $12-42$ & $\begin{array}{l}1986 \\
1991 \text { (less- } \\
\text { shortening) }\end{array}$ \\
\hline $\begin{array}{l}\text { Palmaz- } \\
\text { Schatz }\end{array}$ & Slotted tube & Balloon-expandable & $\begin{array}{l}\text { Premounted } \\
\text { and unmounted }\end{array}$ & $\begin{array}{l}\text { Over-the-wire } \\
\text { and both }\end{array}$ & $3.0-4.0$ & $8-18$ & $\begin{array}{l}1988 \\
1994 \text { (heparin- } \\
\text { coated) }\end{array}$ \\
\hline $\begin{array}{l}\text { Gianturco- } \\
\text { Roubin }\end{array}$ & $\begin{array}{l}\text { Incomplete coil } \\
\text { clam-shell loop }\end{array}$ & Balloon-expandable & Premounted & Over-the-wire & $2.5-4.0$ & $20-40$ & $\begin{array}{l}1989(\mathrm{GR}-1) \\
1995(\mathrm{GR}-1 \mathrm{l})\end{array}$ \\
\hline Wiktor & $\begin{array}{l}\text { Sinusoidal } \\
\text { helical coil }\end{array}$ & Balloon-expandable & Premounted & $\begin{array}{l}\text { Over-the-wire } \\
\text { or monorail }\end{array}$ & $3.0-4.5$ & 16 & $\begin{array}{l}1991 \\
1995 \text { (short- } \\
\text { wave) }\end{array}$ \\
\hline Multi-Link & $\begin{array}{l}\text { Multiple rings with } \\
\text { multiple links }\end{array}$ & Balloon-expandable & Premounted & Over-the-wire & $3.0-3.5$ & 15 & 1993 \\
\hline Cordis & $\begin{array}{l}\text { Sinusoidal } \\
\text { helical coil }\end{array}$ & Balloon-expandable & Premounted & Over-the-wire & $3.0-4.0$ & 15 & 1994 \\
\hline AVE Micro & $\begin{array}{l}\text { Zigzag axial } \\
\text { struts }\end{array}$ & Balloon-expandable & Premounted & Monorail & $2.5-4.0$ & $6-36$ & $\begin{array}{l}1994 \text { (Micro-l) } \\
1995 \text { (Micro-ll) }\end{array}$ \\
\hline NIR & $\begin{array}{l}\text { Expandable uniform } \\
\text { cellular mesh }\end{array}$ & Balloon-expandable & Unmounted & Both & $2.0-5.0$ & $9-32$ & 1995 \\
\hline
\end{tabular}

less" delivery system in combination with the free, unconnected wire-mesh design, render the Wallstent one of the most trackable, pushable, and flexible stents for negotiating tortuous ves- sel and passing through proximally deployed stents (Fig 2). Furthermore, recent modification of the delivery system allows recapture of the stent before final deployment and also allows

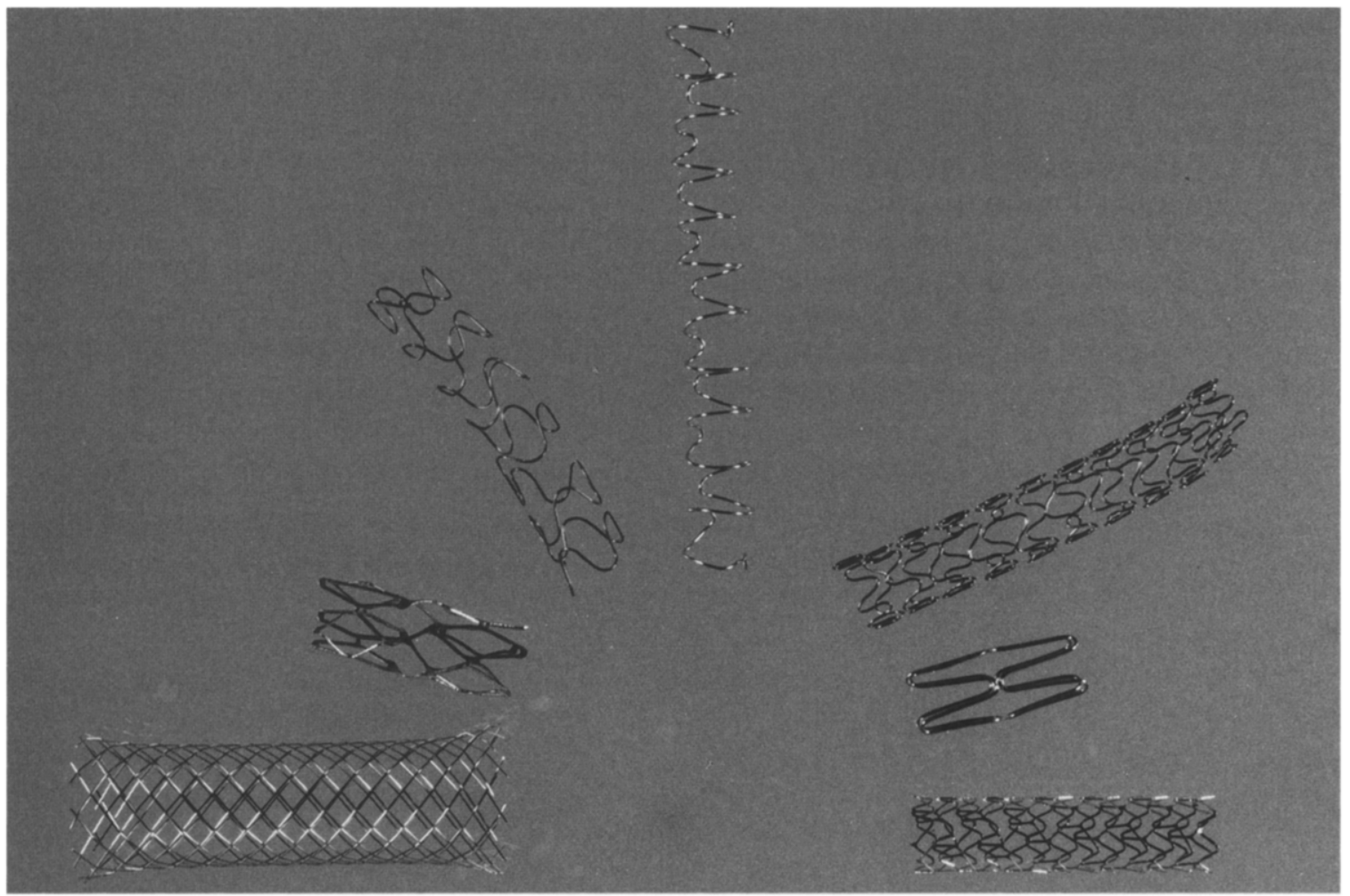

Fig 1. Coronary stents that have undergone clinical evaluation are shown clockwise from the left: Wallstent, Paimaz-Schatz, Wiktor, Gianturco-Roubin, Cordis, AVE Micro, and ACS Multi-Link. (Reprinted with permission. ${ }^{3}$ ) 

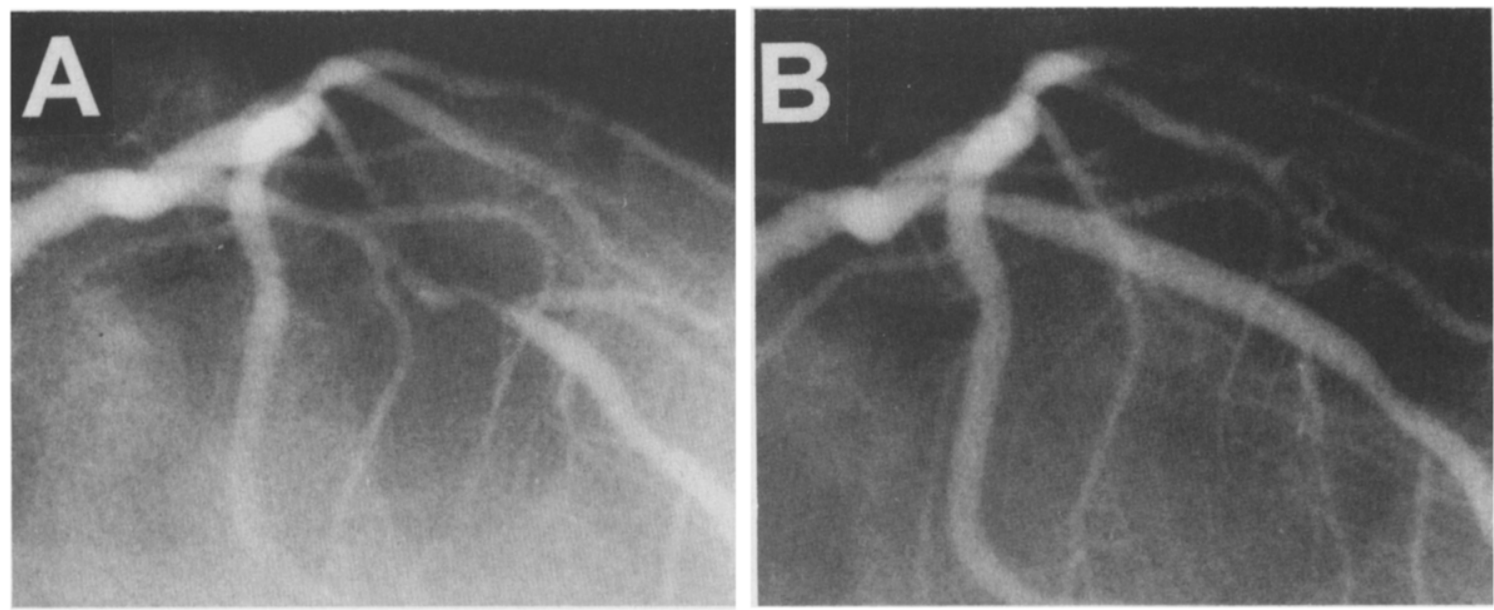

Fig 2. (A) Long complex stenosis in left anterior descending artery before intervention. (B) Flnal angiographic outcome after the deployment of the new less-shortening Wallstent. Note the smooth contour stented segment with no loss of side branches and the absence of vessel sprinting that may be obseved after the deployment of a more rigid stent.

improved positioning, raising the possibility for the use of shorter Wallstents in clinical practice. Its fine cross-hatched mesh design provides excellent scaffolding properties particularly wellsuited to entrap friable material in diffusely diseased vein grafts. Additionally, enforced mechanical remodeling produced by oversizing Wallstent implantation conveys a favorable 6-month clinical and angiographic outcome in both stenosis and total occlusions in native coronary arteries. ${ }^{7,8}$ Its primary limitations are the longitudinal shortening of the stent on radial expansion and motion of the stent during retraction of the rolling membrane, thus rendering the stent less suitable for ostial lesions.

\section{Palmaz-Schatz Stent}

The Palmaz-Schatz stent (Johnson \& Johnson Interventional Systems, Warren, NJ) has been extensively investigated in a broad range of coronary lesions. ${ }^{9-18}$ It is the only stent to date to have completed prospective randomized trials comparing the clinical and angiographic outcome with that of balloon angioplasty. ${ }^{1,2}$ The angiographic results after Palmaz-Schatz stent implantation are predictable, and the slottedtube design allows the performance of highpressure intrastent balloon inflations without risk of structural deformation. However, the low radiopacity of the Palmaz-Schatz stent can render the positioning of a noncompliant balloon for postdeployment, high-pressure, intrastent inflations difficult. Additionally, a higher incidence of restenosis has been reported at the site of the central articulation. ${ }^{19}$ To overcome this limitation, a recent model has been developed without the central articulation (spiral articulation design). This model has a higher radiopacity compared with that of the standard single articulation design. The availability of a free, unmounted Palmaz-Schatz stent that can be crimped by the operator on any balloon provides more procedural versatility and results in a lower profile during stent delivery. However, it does increase the risk of losing the stent during deployment.

\section{Gianturco-Roubin Stent}

Before obtaining Food and Drug Administration (FDA) approval for noninvestigational clinical use, most of the clinical data on the Gianturco-Roubin stent (Cook, Inc, Bloomington, IN) was gathered in single and multicenter registries in the United States. ${ }^{20-25}$ The indication for the Gianturco-Roubin stent for which most data have been gathered is for the bailout of subocclusive and occlusive dissections after balloon angioplasty in native coronary arteries. The data gathered compare well with the data from historical controls treated by repeated and prolonged balloon angioplasty alone. The results of the first randomized trial of the Gianturco-Roubin stent in bailout therapy (GianturcoRoubin stent in Acute Closure Evaluation [GRACE]) are awaited with interest. ${ }^{26}$ The principle advantages of the Gianturco-Roubin 
stent include its range of lengths and longitudinal flexibility. Although the relatively large interstrut intervals of $1 \mathrm{~mm}$ raise questions over the suitability of this stent for the management of friable vein graft lesions, the advantages of the Gianturco-Roubin stent design include minimal risk of "jailing" side branches and the potential to perform coronary interventional procedures in side branches through the interstrut spaces. Whereas this stent excels in long dissections in curved coronary segments (Fig 3), its more generalized use was hindered by the high profile of the first generation. The new

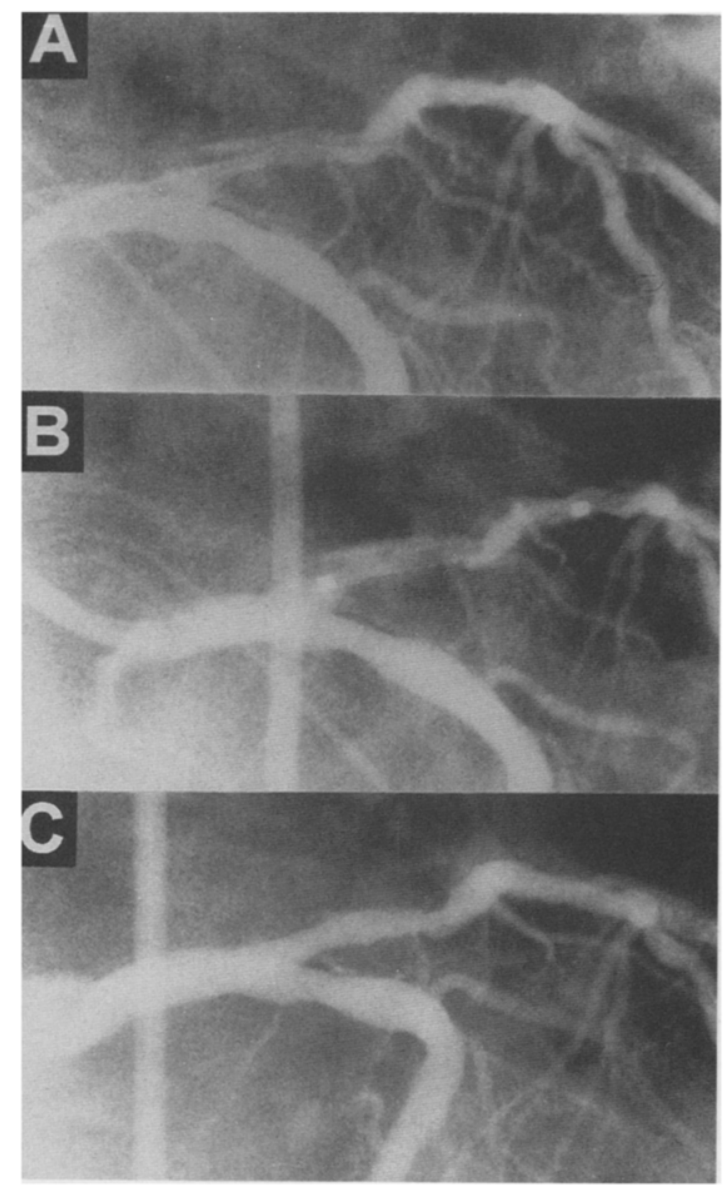

Fig 3. (A) Dissection after balloon angioplasty in the proximal left anterior descending artery is shown. (B) After delivery of a Gianturco-Roubin Flexstent through a Superflow 8-French Judkins guiding catheter (Cordis) to the target vessel, the radiopaque markers (located $1 \mathrm{~mm}$ proximal and distal to the stent extremities) facilitate the final positioning of the stent before inflation of the delivery balloon. (C) Contrast angiography poststent deployment shows preservation of the vessel curvature in the stented segment. (Reprinted with permis. sion. ${ }^{3}$ generation flex-II stent overcomes these problems with a lower profile and a higher visibility.

\section{Wiktor Stent}

The available clinical data on the Wiktor stent (Medtronic, Minneapolis, $\mathrm{MN}$ ) arises from observational studies and registry data, ${ }^{27-30}$ the principle registry of which has been in the management of restenotic lesions. Similar to the Gianturco-Roubin stent, the Wiktor stent is a coil stent that offers marked flexibility and, thus, conformability with the vessel curvature. However, also similar to the Gianturco-Roubin stent, the Wiktor stent is unlikely to excel in the treatment of friable vein grafts because of the large interstrut interval and the subsequently reduced scaffolding properties. The radiopacity of the Wiktor stent allows exquisite positioning of the stent in ostial and focal lesions, and the flexibility of the stent makes it suitable for short dissections on curved coronary segments. The recent introduction of the option of a monorail delivery system improves the user-friendliness of the device. The limitations of the initial prototype of the Wiktor stent included the availability of only one length and the limited scaffolding properties with the potential for the protrusion of intimal flaps through the interstrut intervals. These limitations have been overcome by the new generation, short-waveform Wiktor stent, although the radiopacity of this tantalum stent can still interfere with online quantitative angiographic analysis of the stented segment. ${ }^{31}$

\section{Multi-Link Stent}

At present, the ACS Multi-Link stent (Advanced Cardiovascular Systems, London, UK) has the least clinical experience of the currently available stents, having just completed its first 100-patient registry conducted at five European centers. ${ }^{32}$ The advantages of this new stent include the flexibility and low profile of the sheathed stent and delivery system. Although the Multi-Link stent design manages to provide remarkable scaffolding properties, the metallic burden to the stented vessel remains very low by virtue of the small diameter of the corrugated struts. The limitations of the stent include its radiolucency, which renders the positioning of noncompliant balloons for postdelivery, high- 
pressure intrastent inflations very difficult. The current availability of only one length of $15 \mathrm{~mm}$ means that the first prototype can only be used for very focal lesions. After some minor modifications, this stent may offer some significant advantages over the earlier generation of stent designs. The attachment of radiopaque tips on the stent would present a significant enhancement.

\section{AVE Micro Stent}

The AVE Micro stent (Applied Vascular Engineering, Santa Rosa, CA) is now undergoing clinical evaluation in a large number of countries. ${ }^{33}$ The high degree of radiopacity and balloon-expandable deployment should render this stent ideal for exquisite positioning in highly focal and ostial lesions (Fig 4). However, by virtue of the longitudinal (axial) orientation of its eight struts, the 4-mm AVE Micro stent units may be prone to proximal migration and protrusion; therefore, preferably longer, welded AVE Micro stents should be deployed in ostial locations. The customized range of short lengths make the AVE Micro stent ideal as an adjunctive complementary device for multiple stenting, filling in the gaps between longer stents, and improving the inflow or outflow of longer stents. Additionally, the high flexibility and low thrombogenecity of the AVE micro stent make it an ideal stent for bailout management after failed balloon angioplasty. ${ }^{33}$ Despite the $a b-$ sence of a protective sheath, the low profile and longitudinal strut orientation make the AVE micro stent one of the easiest stents to pass through other proximally deployed stents. The monorail delivery system increases the userfriendliness of the device, which has a short learning curve. The strong radial support proffered by the thick struts should make the stent suitable for the prevention of recoil and restenosis. However, care should be taken to avoid the positioning of junctions between the unconnected $4-\mathrm{mm}$ units at the site of the minimal lumen diameter of lesions to prevent intimal protrusion. Recent developments include the helicoildal welding of multiple 3-mm-length units (Micro stent-II) to provide multiple lengths of up to $36 \mathrm{~mm}$.

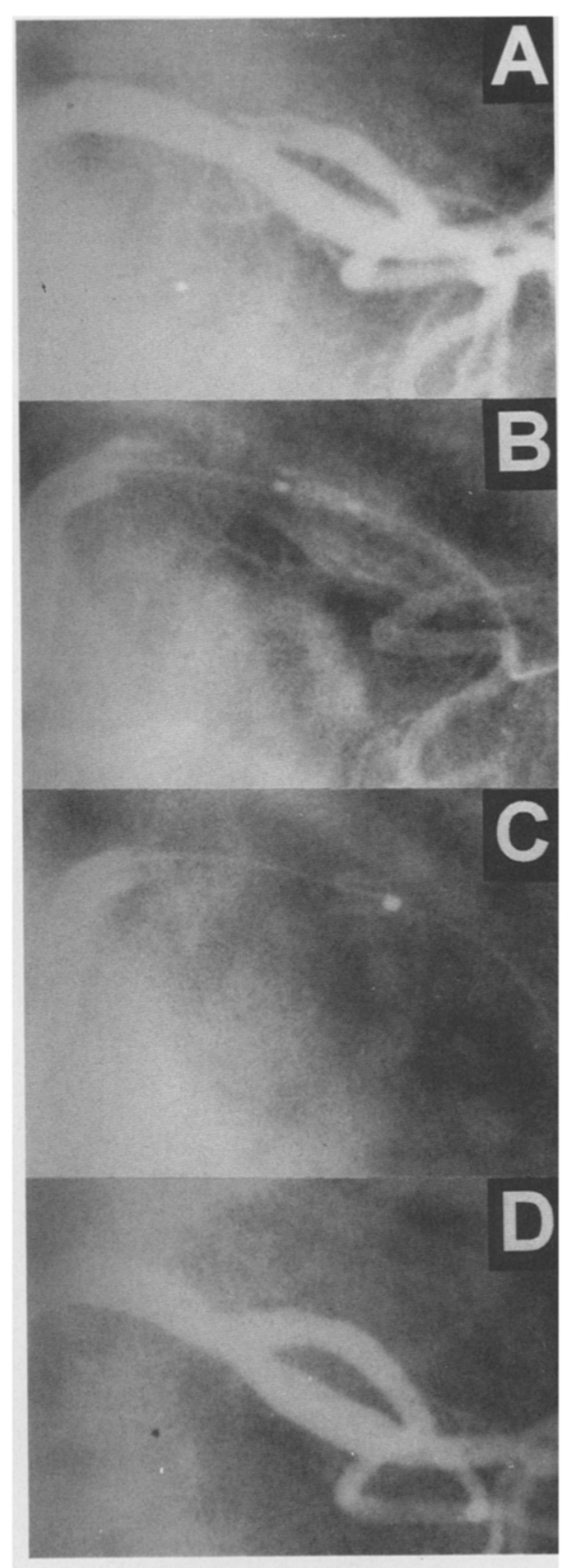

Fig 4. (A) Short dissection in the origin of the left circumflex coronary artery after balloon angioplasty is shown. (B) An AVE Micro stent is delivered to the target vessel through an 8-French Amplatz guiding catheter (Schneider Scientific, Watertown, MA). The two radiopaque markers at the extremities of the stent are clearly seen. (C) After delivery of the stent, the thick radiopaque stainless-steel struts facilitate the precise positioning of a short noncompliant balloon (single marker) within the stent for subsequent high-pressure inflations and optimization of stent deployment. (Reprinted with permission. $\left.{ }^{3}\right)$ 


\section{Cordis Stent}

The Cordis stent (Cordis, Miami, FL) continues to undergo early evaluation in the clinical arena. ${ }^{31}$ Similar to the ACS stent, the Cordis stent offers some advantages over the first generation stents by virtue of its low profile, flexibility, and comprehensive scaffolding properties. However, the absence of a protective sheath on the delivery system increases the possibility of stent dislodgement or disruption during delivery. The operator should be aware of the protrusion of the delivery balloon beyond the limits of the Cordis stent if inflations of higher pressure are considered. Although the strongly radiopaque tantalum struts allow exquisite positioning (Fig 5) of the stent in short dissections in curved coronary segments, the radiopacity may pose problems for on-line quan- titative angiographic assessment, particularly during assessment of luminal renarrowing at 6-month angiographic follow-up examination. ${ }^{31}$ The relative merits of this stent are currently being evaluated in a European multicenter registry and by Hamasaki et al in Japan. ${ }^{34}$

\section{NIR Stent}

The NIR stent (Medinol, Tel Aviv, Israel) is a recently developed balloon-expandable stent currently undergoing clinical evaluation in some centers in Israel and Europe. Although this stent has a low radiopacity, the stent has a high flexibility and comes in a wide range of customized sizes (diameter, 2 to $5 \mathrm{~mm}$ ) and lengths (9 to $32 \mathrm{~mm}$ ). Balloon-unmounted models allow for the choice of various types of balloon for stent delivery and may spare the usage of an

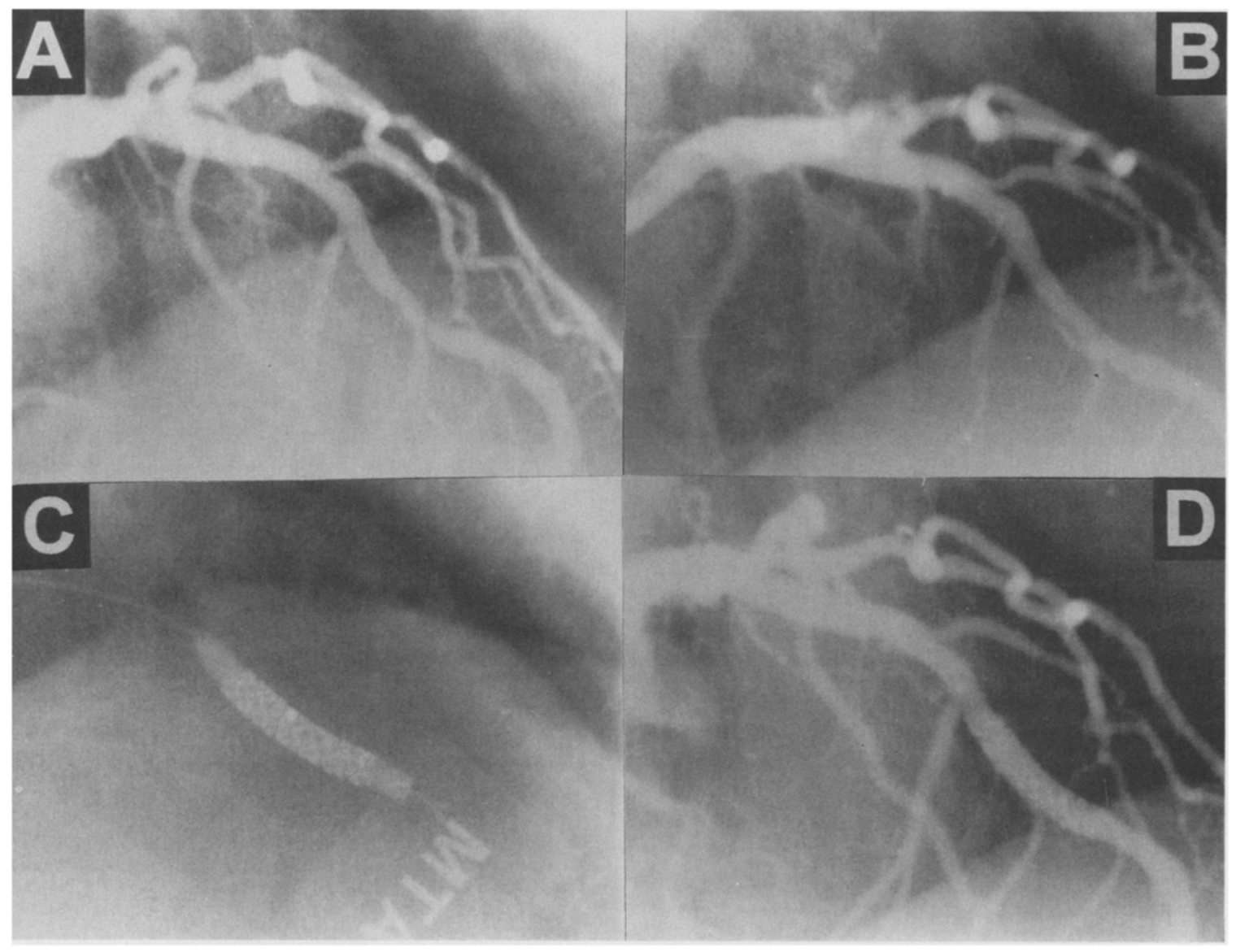

Fig 5. (A) The left coronary artery lesion located at the bifurcation is shown. (B) Postballoon angioplasty dissection type $\mathrm{C}$ was clearly seen. (C) Positioning of the Cordis stent was facilitated by the radiopacity of the tantalum struts, which are clearly seen during inflation of the contrast-filled intrastent balloon to $\mathbf{1 0} \mathrm{atm}$. (D) Angiography after stent deployment shows the stent struts to be embedded in the vessel wall external to the contour of the contrast-filled lumen. 
additional balloon catheter only for stent delivery. A preliminary report indicates a high deployment success rate despite the fact that most of the lesions were difficult to treat because of vessel tortuosity, distal location, and long lesion length. ${ }^{35}$ The restenosis rate has not yet been determined.

\section{FUTURE STENTS}

All currently available stents are composed of metal, and the long-term effects of their implantation in the coronary arteries are still not clear. Because of the metallic surface, they are thrombogenic; therefore, rigorous antiplatelet or anticoagulant therapy is theoretically required. Furthermore, they represent an imperfect compromise between scaffolding properties and flexibility, resulting in an unfavorable interaction between stent and unstable plaque or thrombus burden. Finally, they still induce substantial intimal hyperplasia that may result in restenosis. Future stents can be made less thrombogenic by modifying the metallic surface or coating it with an antithrombotic agent or a membrane eluting an antithrombotic drug. The unfavorable interaction with the unstable plaque and the thrombus burden can be overcome by covering the stent with a biological conduit, such as a vein, or a biodegradable material that can be endogenous, such as fibrin, or exogenous, such as a polymer. Finally, the problem of persisting induction of intimal hyperplasia may be overcome with the use of either a radioactive stent or a stent eluting an antiproliferative drug.

\section{Coated Stents}

Metal coated. In vitro work suggests that surface potential may exert a substantial effect on both the thrombogenicity and antiproliferative effect of metals. High surface potential is associated with pronounced attraction of negatively changed particles such as platelets and plasma proteins, thus resulting in high thrombogenicity. Conversely, however, metals with high surface potential have a substantial antiproliferative effect on fibroblasts, suggesting that, by varying surface charge, we may be able to influence the thrombogenicity and neointimal hyperplasia after stent implantation. One way of accomplishing this would be by modifying the base metal. ${ }^{36}$

Metals can be modified either by galvanization or by ion bombardment. Galvanization involves the electrochemical deposition of metal $3.3 \mu \mathrm{m}$ in thickness on the stent and results in $100 \%$ of the stent surface being covered before stent expansion. Ion bombardment consists of spluttering a thin metal film onto the stent followed by a bombardment with argon ions. The resulting implantation of metal onto the stent surface increases the thickness by $20 \mathrm{~nm}$, and $75 \%$ stent surface coverage is required before expansion.

Preliminary experience suggests that coating steel stents with platinum, gold, or copper results in higher in vitro surface potentials but that the incidence of thrombosis in vivo is increased, particularly in stents coated using galvanization. ${ }^{36}$ Thus, in contrast to the in vitro suggestion, metal charge does not seem to play a major role in stent thrombogenicity in vivo. Furthermore, a low stent charge appeared to correlate with increased neointimal formation. Therefore, modifying stainless steel stents by covering them with gold, platinum, or copper is unlikely to be the solution to increased thrombogenicity or neointimal hyperplasia.

Cell seeding of stents. Coating of metallic stents with endothelial cells, particularly genetically engineered cells with increased cell surface fibrinolytic activity, may improve their thrombogenic nature. Preliminary work has shown the feasibility of this approach..$^{37,38}$ More recently, in vitro work suggests that genetically engineered endothelial cells would allow increased fibrinolysis to be promoted by the surface localization of urokinase.$^{39}$ However, questions remain concerning the number of cells that will remain attached under flow conditions and the legal responsibility in case of failure of endothelial cell function.

Immobilized drug coatings. Coating of the stent surface with an antithrombotic agent such as heparin ${ }^{40-42}$ provides a novel solution to the problem of increased thrombogenicity of metallic stents and the subsequent need for intensive anticoagulation that results in increased morbidity and costs. After encouraging preliminary experience with a heparin-coated PalmazSchatz stent in pig coronary arteries, the Bene- 
stent-II study evaluated the safety of reducing and eliminating anticoagulant therapy in patients receiving a heparin-coated stent. Initial results from the pilot study suggest that subacute stent thrombosis does not occur using the heparin-coated stent, which virtually eliminated the bleeding complications after stent implantation and reduced the in-hospital stay to 3 days. ${ }^{43}$ The 6-month angiographic follow-up examination also indicates that these coated stents do not induce excess of intimal hyperplasia. ${ }^{44}$ The results of follow-up studies in which coumadin and heparin are replaced by ticlodipine and aspirin are awaited.

Polymer-coated stents. The stent metal surface can be rendered less thrombogenic by coating it with a thin layer of a synthetic polymer. Initial results suggested that, although this may protect against acute thrombotic events, it does not reduce the extent of subsequent neointimal hyperplasia. ${ }^{45}$ However, the advantage of a polymer-coated stent is that it can be loaded with antithrombotic or antiproliferative agents directed against the neointimal reparative process (Fig 6). ${ }^{46}$

Fibrin stent. The fibrin-film stent has several theoretical advantages. It is a membrane stent and thus can cover the balloon angioplasty injury site, thereby providing a natural healing matrix while reducing local thrombus formation. It may also be useful in vein grafts in which

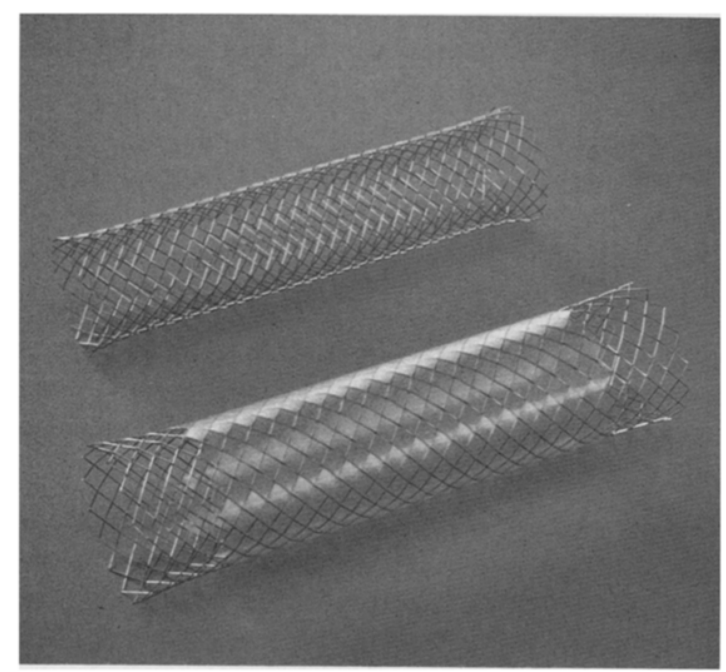

Fig 6. An eluting stent consisting of a stent surrounded by an elastic sleeve made of biodegradable polymer loaded with $40 \%$ antithrombotic agent is shown. the membrane may prevent distal embolization of friable material. Preliminary work suggests that the fibrin-film stent is both bioabsorbable and biocompatible. ${ }^{47}$ It also appears to be safe in pigs with the use of an antiplatelet agent. However, it had little effect on neointimal proliferation.

Vein-coated stents. An autologous vein graftcoated stent consisting of a conventional stent covered by a vein graft may be the ideal conduit for percutaneous revascularization, thus minimizing stent thrombogenicity and local tissue reaction to the stent. Preliminary experience in 13 patients suggests that the technique is feasible and safe, resulting in an excellent immmediate angiographic result, ${ }^{48}$ but further studies are warranted to investigate the effect of the procedure on subacute thrombosis and longterm restenosis.

\section{Nitinol Stent}

Nitinol has a number of properties that make it ideal for stent composition. It is known to be highly biocompatible and highly malleable, allowing 0.006-in struts without sacrificing flexibility. Furthermore, it has unique thermoelastic properties that allow for stent collapse and removal as well as for self-expansion. ${ }^{49-52} \mathrm{Fi}$ nally, it is amenable to surface coating for local drug delivery and is transmutable into a radioactive emitter for local radiation therapy. Preliminary work in a pig coronary subacute thrombosis model has confirmed some of these theoretical advantages of a nitinol stent showing that nitinol stents, particularly polished nitinol stents, develop significantly less thrombus (as measured by thrombus weight and thrombus grade) in comparison with that for stainless steel stents of similar design. ${ }^{49}$ The results on neointimal hyperplasia are still awaited, although preliminary results from a separate group suggest that a self-expanding nitinol stent exerts a more favorable effect on vascular remodeling and neointimal formation than does a balloonexpandable, tubular, slotted stent. ${ }^{50}$ Initial experience in 20 patients suggests that a nitinol stent is safe and effective in the treatment of suboptimal results. ${ }^{52}$

\section{Polymer Stent}

Polymer stents have several potential advantages. They can be loaded with antithrombotic 
and/or antiproliferative pharmaceutical agents in high concentration for sustained local delivery. They may have less of a mechanical mismatch with the vessel wall than do metal stents and may avoid the potential for late-stage complications. Therefore, polymer stents have a synergistic mechanical and local pharmacological effect that provides sustained structural support throughout the healing phase, thus potentially avoiding early and late elastic recoil while the local high-dose drug delivery potentially prevents thrombosis, neointimal proliferation, and systemic side effects. However, there is only limited strength if a large percentage of drug is loaded onto the stent. Initial animal experiments, however, have shown a marked inflammatory response resulting in substantial luminal encroachment with polymer stents in porcine coronary arteries..$^{53,54}$ However, there is no vascular tissue reaction with high molecular weight poly-l-lactic acid, and this remains a promising avenue of investigation.

\section{Composite (Metal-Augmented) Polymer Stents}

Composite polymer stents guarantee a minimal mechanical mismatch between the stent and the vessel wall, leaving a delicate metal skeleton after biodegradation. They provide protection of tissues from deep strut laceration and large amounts of drug (up to $40 \%$ ) for slow local release without affecting hoop strength. Such a composite polymeric stent, capable of excellent mechanical strength as well high-dose local drug delivery, has been developed and evaluated in porcine coronary arteries. Preliminary histological analysis showed that neointimal hyperplasia and some degree of inflammatory response were present in all groups. Unfortunately, implantation of bicomponent stents caused a reduction in lumen diameter for all designs. Further research will assess the relative contributions of stent geometry, polymer type, and incorporated drug to the overall response.

\section{Radioactive Stents}

Radiation selectively kills proliferating cells independent of the stimulus for cell growth. Because a major cause of restenosis is neointimal hyperplasia secondary to vascular smooth muscle cell proliferation, it seems reasonable to assume that radiation therapy may reduce restenosis. Multiple animal studies have now confirmed the ability of radiation therapy to inhibit neointimal hyperplasia and reduce restenosis. ${ }^{55,56}$ Radioactive stents have the potential to deliver an appropriate dose of radiotherapy to the area of interest, thus reducing restenosis while minimizing the total dose administered to the patient.

Two methods are currently in use. In the first method, conventional Palmaz-Schatz stents are bombard with ions in a cyclotron and subsequently emit low-dose $\beta$ and $\gamma$ radiation from radioisotopes Co55, 56, 57, Mn52, and Fe55, with half-lives between 17.5 hours and 2.7 years. ${ }^{57}$ The radiation is predominantly short range, is homogeneously distributed over the length and circumference of the stent, and is absolutely fixed to the metal. For this reason, the stents do not require a license from the International Atomic Energy Agency (Vienna, Austria). An intimal surface dose rate of 4 $\mathrm{mGy} / \mathrm{h}$ results in an integral dose of $180 \mathrm{mGy}$ after a period of 100 days.

Low-dose radioactive stents were found to markedly inhibit neointimal hyperplasia in rabbits. Endothelialization of the radioactive stents was found to be delayed with macrophages being located on top of the radioactive stent struts until endothelialization was complete. Although the degree of neointimal hyperplasia was reduced, it was found, paradoxically, that extracellular matrix production increases after radioactive stent implantation. ${ }^{57}$

The second method is uses $\beta$ particles. ${ }^{58,59} \beta$ Particles (free electrons) may represent the ideal means of local irradiation. $\mathrm{P}^{32}$ is an excellent candidate for local delivery because the maximal range of $\beta$ particles is 3 to $4 \mathrm{~mm}$ in tissue. It has a desirable half-life of 14.3 days, and, once implanted after balloon angioplasty, there is no detectable radiation by 4 months. $\mathrm{P}^{32}$ or other $\beta$ emitters can also be implanted directly onto the stent wire.

Such $\mathrm{P}^{32}$-impregnated stents have been now fabricated. In vitro work suggests that very low $\beta$-particle activity levels inhibit smooth muscle cell growth preferentially within a 5- to 7-mm radius of the $P^{32}$-coated stent wires, whereas endothelial cells appear to be much more radioresistant. In vivo animal testing in a porcine 
restenosis model using low-dose rate $\mathrm{P}^{32}$ stents have shown inhibition of neointimal growth. ${ }^{58}$

A $\mathrm{P}^{32}$-coated stent with doses similar to those described should be safe in humans. Total-body dosimetry to the patient would be less than $1 / 1000$ that of fluoroscopy during angioplasty. Furthermore, the radiation would be local and would not reach any mediastinal tissues. Additionally, the radiation to the interventionalist will be much less than that occurring with fluoroscatter.

\section{CONCLUSIONS}

The stent represents the second generation of coronary angioplasty. It is a predictable therapy for bailout that improves a suboptimal result and reduces the risk of restenosis. As a result of these advantages, over $40 \%$ of coronary interventional procedures in the current year will include stent implantation. However, the currently available stents have a number of limitations that are being addressed. Drugeluting stents that address the problem of the small vessel and low-flow situations are on the horizon. Covered stents in which a membrane acts as an isolating barrier that minimizes local thrombus formation and delivers local drug therapy are promising. Radioactive stents to inhibit local neointima formation are another promising avenue of investigation. Biodegradable stents and composite stents are also being actively investigated.

\section{REFERENCES}

1. Serruys PW, de Jaegere P, Kiemeneij F, et al on behalf of the Benestent Study Group: A comparison of balloonexpandable-stent implantation with balloon angioplasty in patients with coronary artery disease. $\mathrm{N}$ Engl J Med 331:489-495, 1994

2. Fischman DL, Leon MB, Baim DS, et al: A randomized comparison of coronary-stent placement and balloon angioplasty in the treatment of coronary artery disease. $\mathrm{N}$ Engl J Med 331:496-501, 1994

3. Keane D, Serruys PW: Different stents for different coronary lesions, in Rowlands DJ (ed): Recent Advances in Cardiology. London, UK, Churchill Livingstone, 1995

4. Sigwart U, Puel J, Mirkovitch V, et al: Intravascular stents to prevent occlusion and restenosis after transluminal angioplasty. N Engl J Med 316:701-706, 1987

5. Serruys PW, Strauss BH, Beatt KJ, et al: Angiographic follow-up after placement of a self-expanding coronary artery stent. N Engl J Med 334:13-17, 1991

6. Keane D, de Jaegere P, Serruys PW: Structural design, clinical experience and current indications of the coronary Wallstent. Cardiol Clin 12:689-697, 1994

7. Ozaki Y, Keane D, Ruygrok P, et al: Six-month clinical and angiographic outcome of the new less shortening Wallstent in native coronary arteries, Circulation 93:2114 2120,1996

8. Ozaki Y, Violaris AG, Hamburger JN, et al: Shortand long-term clinical and quantitative angiographic results with the new less shortening Wallstent for vessel reconstruction in chronic total occlusion. J Am Coll Cardiol 1996 (in press)

9. Schatz RA, Baim DS, Leon M, et al: Clinical experience with the Palmaz-Schatz coronary stent: Initial results of a multicenter study. Circulation 83:148-161, 1991

10. Hermann $\mathrm{HC}$, Buchbinder $\mathrm{M}$. Clemen $\mathrm{M}$, et al: Emergent use of balloon-expandable stenting for failed percutaneous transluminal coronary angioplasty Circulation 86:812-819, 1992

11. Colombo A, Goldberg SL, Almagor Y, et al: A novel strategy for stent deployment in the treatment of acute or threatened closure complicating balloon coronary angio- plasty. Use of short or standard (or both) single or multiple Palmaz-Schatz stents. J Am Coll Cardiol 22:1887-1891, 1993

12. Haude $M$, Erbel $R$, Issa $H$, et al: Quantitative analysis of elastic recoil after balloon angioplasty and after intracoronary implantation of balloon expandable PalmazSchatz stents. J Am Coll Cardiol 21:26-34, 1993

13. Goldberg SL, Colombo A, Nakamura S, et al: Benefit of intracoronary ultrasound in the deployment of Palmaz. Schatz stents. J Am Coll Cardiol 24:996-1003, 1994

14. Schömig A, Kastrati A, Dietz R, et al: Emergency coronary stenting for dissection during percutaneous transluminal coronary angioplasty: Angiographic follow-up after stenting and after repeat angioplasty of the stented segment. J Am Coll Cardiol 23:1053-1060, 1994

15. Nakamura S, Colombo A, Gaglione A, et al: Intracoronary ultrasound observations during stent implantation. Circulation 89:2026-2034, 1994

16. Mudra $H$, Blasini $R$, Kroetz $M$, et al: Ultrasound guidance of Palmaz-Schatz intracoronary stenting with a combined intravscular ultrasound balloon catheter. Circulation 90:1252-1261, 1994

17. Wong SC, Popma JJ, Pichard AD, et al: A comparison of clinical and angiographic outcomes after saphenous vein graft angioplasty using coronary versus "biliary" tubularslotted stents. Circulation 91:339-350, 1995

18. Colombo A, Hall P, Nakamura S, et al: Intracoronary stenting without anticoagulation accomplished with intravscular ultrasound guidance. Circulation 91:1676-1688, 1995

19. Ikai $Y$, Yamaguchi $T$, Tamura $T$, et al: Site of restenosis in Palmaz-Schatz coronary stent. Circulation 88:I-641, 1993 (abstr, suppl I)

20. Roubin GS, Cannon AD, Agrawal SK, et al: Intracoronary stenting for acute and threatened closure complicating percutaneous transluminal coronary angioplasty. Circulation 85:916-927, 1992

21. Lincoff AM, Popma JJ, Ellis SG, et al: Abrupt vessel closure complicating coronary angioplasty: Clinical, angiographic and therapeutic profile. I Am Coll Cardiol 19:926935,1992

22. Hearn AJ, King SB, Douglas JS, et al: Clinical and 
angiographic outcomes after coronary artery stenting for acute or threatened closure following percutaneous transluminal coronary angioplasty. Initial results with a balloonexpandable stainless steel design. Circulation 88:2086-2096, 1993

23. Lincoff AM, Topol EJ, Chapekis AT, et al: Intracoronary stenting compared with conventional therapy for abrupt vessel closure complicating coronary angioplasty: A matched case-control study. J Am Coll Cardiol 21:866-875, 1993

24. George BS, Voorhees WD, Roubin GS, et al: Multicenter investigation of coronary stenting to treat acute or threatened closure after percutaneous transluminal coronary angioplasty: Clinical and angiographic outcomes. J Am Coll Cardiol 22:135-143, 1993

25. Sutton JM, Ellis SG, Roubin GS, et al for the Gianturco-Roubin Intracoronary Stent investigator Group: Major clinical events after coronary stenting. Circulation 89:1126-1137, 1994

26. Keane D, Roubin G, Marco J, et al: GRACEGianturco-Roubin stent in Acute Closure Evaluation: Substrate, challenges and design of a randomized trial of bailout therapy. J Intervent Cardiol 7:333-339, 1994

27. Serruys PW, de Jaegere P, Bertrand M, et al: Morphologic change in coronary artery stenosis with the Medtronic Wiktor stent: Initial results from the core laboratory for quantitative angiography. Cathet Cardiovase Diagn 24:237. 245,1991

28. de Jaegere P, Serruys PW, Bertrand M, et al: Wiktor stent implantation in patients with restenosis following balloon angioplasty of a native coronary artery. Am J Cardiol 69:598-602, 1992

29. de Jaegere P, Serruys PW, Bertrand M, et al: Angiographic predictors of recurrence of restenosis after Wiktor stent implantation in native coronary arteries. Am J Cardiol 72:165-170, 1993

30. Medina A, Melian F, Saurez de Lezo J, et al Effectiveness of coronary stenting for the treatment of chronic total occlusion in angina pectoris. Am $\mathrm{J}$ Cardiol 73:1222-1224, 1994

31. Ozaki Y, Keane D, Nobuyoshi M, et al: Coronary lumen at 6 month follow-up of the new radiopaque tantalum stent using quantitative angiography and Intracoronary ultrasound. Am J Cardiol 76:1135-1142, 1995

32. Sigwart U, Haber RH, Kowlachuk GJ, et al: The new ACS metallic stent: Experimental and clinical experience. Circulation 88:I-646, 1993 (abstr, suppl I)

33. Ozaki Y, Keane D, Ruykrok P, et al: Acute clinical and angiographic results with the new AVE micro coronary stent in bailout management. Am J Cardiol 76:112-116, 1995

34. Hamasaki N, Nosaka H, Nobuyoshi M: Initial experience of Cordis stent implantation. I Am Coll Cardiol 25:239A, 1995 (abstr, suppl)

35. Almagor Y, Richter K, Di Mario C, et al: Treatment of long lesions in small tortuous coronary vessels with a new intravascular rigid-flex (NIR) stent. J Am Coll Cardiol 27:110A, 1996 (abstr, suppl)

36. Hehrlein C, Zimmerman M, Grunze M, et al: Characteristics of metallicly modified stents and their influence on neointima formation in rabbits. Eur Heart $\mathfrak{J} 14: 321,1993$ (abstr, suppl)

37. van der Giessen WJ, Serruys PW, Visser WJ, et al:Endothelialisation of intravascular stents. $J$ Intervent Cardiol 1:109-120, 1988

38. Dichek DA, Neville RF, Zwiebel JA, et al: Seeding of intravascular stents with genetically engineered endothelial cells. Circulation 80:1347-1353, 1989

39. Sawa H, Vinogradsky B, Guala A, et al: Genetically engineered endothelial cells; increased surface fibrinolysis and potential application to endovascular stenting. Circulation 92:I-537, 1995 (abstr, suppl)

40. de Scheeder IK, Wang K, Wilczek KL, et al: Heparin coating of metallic coronary stents decreases their thrombogenicity but does not decrease neointimal hyperplasia. Circulation 92:I-537, 1995 (abstr, suppl I)

41. Jeong MHJ, Owen WG, Staab ME, et al: Does heparin release coating of the Wallstent limit thrombosis and platelet deposition? Results in a porcine carotid injury model. Circulation 92:I-37, 1995 (abstr, suppl I)

42. Chronos NAF, Robinson KA, Kelly AB, et al: Thrombogenicity of tantalum stents is decreased by surface heparin bonding: Scintigraphy of IIIn-platelet deposition in baboon carotid arteries. Circulation 92:I-490, 1995 (abstr, suppl I)

43. Heyndrickx GR on behalf of the Benestent Study Group: Benestent II pilot study: In hospital results of phases 1, 2, 3 and 4. Circulation 92:I-279, 1995 (abstr, suppl I)

44. Serruys PW on behalf of the Benestent Study Group: Benestent II pilot study: 6-Month follow up of phases 1, 2, 3 . Circulation 92:I-542, 1995 (abstr, suppl I)

45. van der Giessen WJ, van Beusekom HMM, van Houten $\mathrm{CD}$, et al: Coronary stenting with polymer coated and uncoated self-expanding endoprostheses in pigs. Coron Artery Dis 3:237-248, 1992

46. Aggarwal RK, Ireland DC, Azrin MA, et al: Antithrombotic properties of stents eluting platelet glycoprotein IIb/IIIa antibody. Circulation 92:I-488, 1995 (abstr, suppl I)

47. Schwartz RS, Huber KC, Edwards WD, et al: Native fibrin as a biocompatible absorbable material for intracoronary stent implant and drug delivery. J Am Coll Cardiol 19:171A, 1992 (abstr, suppl A)

48. Stefanadis C, Tsiamis E, Toutouzas K, et al: Autologous vein graft coated stent for the treatment of coronary artery disease: Immediate results after percutaneous implantation in humans. J Am Coll Cardiol 27:179A, 1996 (abstr, suppl A)

49. Sheth S, Litvack F, Fishbein MC, et al: Reduced thrombogenicity of polished and unpolished nitinol versus stainless steel slotted-tube stents in a pig coronary artery model. J Am Coll Cardiol 27:197A, 1996 (abstr, suppl A)

50. Carter AJ, Laird JR, Kovach JA, et al: Favorable arterial remodeling and reduced neointimal formation with a nitinol self-expanding stent. J Am Coll Cardiol 27:109A, 1996 (abstr, suppl A)

51. Henty M, Amor M, Henry I, et al: Initial experience with the Instent Nitinal permanent and temporary stents. Circulation 92:I-57, 1995 (abstr, suppl I)

52. Beyar R, Roguin A, Grenadier E, et al: The nitinol self expanding coronary stent: Acute angiographic and 
clinical results of the pilot registry. J Am Coll Cardiol 27:54A, 1996 (abstr, suppl A)

53. van der Giessen, Lincoff AM, Schwartz RS, et al: Biocompatibility of synthetic biodegradable and biostable polymers after implantation in the porcine coronary arteries. Eur Heart J 14:352, 1993 (abstr, suppl)

54. Eccleston DS, Lincoff AM, Furst JG: Administration of Colchicine using a novel prolonged delivery stent produces a marked local biological effect within the porcine coronary artery. Circulation 92:I-87, 1995 (abstr, suppl I)

55. Waksman R, Robinson KA, Crocker IR, et al: Intracoronary radiation before stent implantation inhibits neointima formation in stented porcine coronary arteries. Circulation 92:1383-1386, 1995
56. Teirstein PS, Massullo V, Jani S, et al: Catheter based radiation therapy to inhibit restenosis following coronary stenting. Circulation 92:I-543, 1995 (abstr, suppl I)

57. Hehrlein C, Zimmerman M, Metz J, et al: Radioac* tive stent implantation inhibits neointimal proliferation in non-atherosclerotic rabbits. Circulation 88:I-65, 1993 (abstr, suppl I)

58. Laird JR, Carter AJ, Kufs WM, et al: Inhibition of neointimal proliferation with a beta particle emitting stent. J Am Coll Cardiol 26:287A, 1995 (abstr, suppl A)

59. Carter AJ, Laird JR, Hoopes TG, et al: Histology after placement of beta particle emitting stents; insights into inhibition of neointimal formation. J Am Coll Cardiol 27:198A, 1996 (abstr, suppl A) 